\title{
Level of knowledge about anaphylaxis and its management among health care providers
}

\author{
H. S. Drupad, H. Nagabushan
}

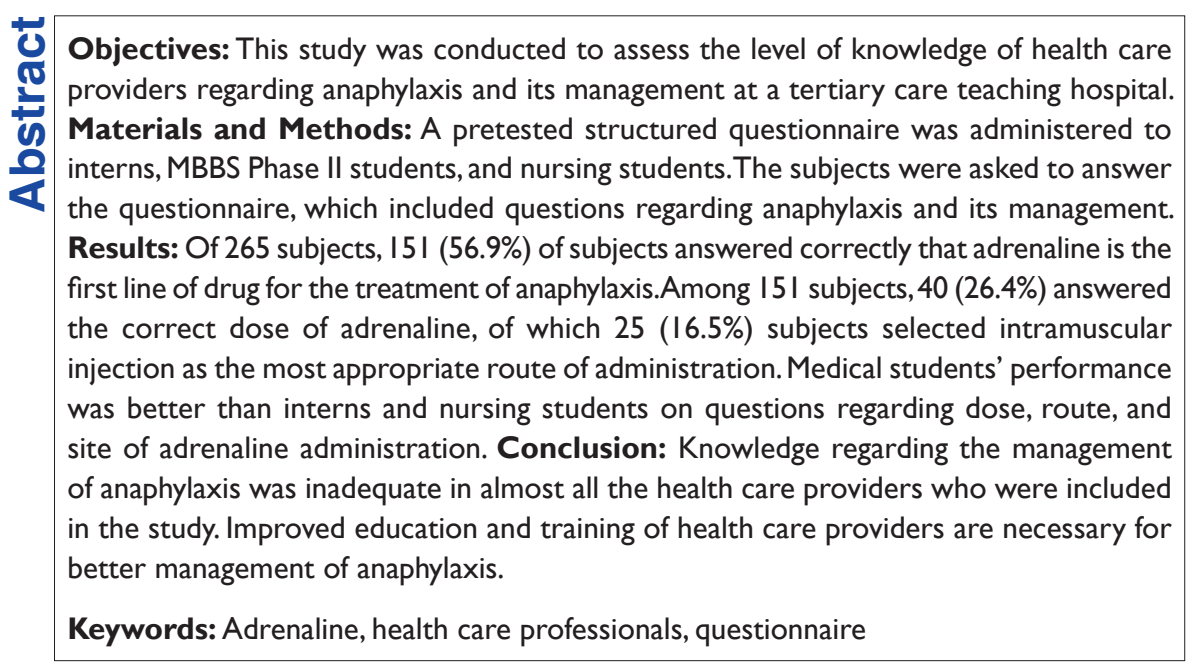

\begin{tabular}{|l|}
\hline Access this article online \\
\hline Website: www.ijccm.org \\
\hline DOI: 10.4103/0972-5229.160288 \\
\hline Quick Response Code: \\
\hline \\
\hline
\end{tabular}

\section{Introduction}

Anaphylaxis is a life-threatening acute generalized systemic reaction. ${ }^{[1]}$ Mast cells are the key effector cell of the biological response to anaphylaxis with the release of various mediators of inflammation. ${ }^{[2]}$ The frequency of anaphylaxis is approximately 50-2000 episodes $/ 100,000$ persons and has a lifetime prevalence of $0.05-2.0 \%{ }^{\left[{ }^{[3]}\right.}$ Recent studies have shown that there is an increase in incidence and prevalence of anaphylaxis over the last 20 years. ${ }^{[4]}$

Adrenaline is the life saving and first line of drug to be used for the treatment of anaphylaxis. ${ }^{[5]}$ Several studies conducted previously reveals that there is a lack of knowledge regarding dose and route of administration of adrenaline and confusion in selecting the first line drug

From:

Department of Pharmacology, Mandya Institute of Medical Sciences, Mandya, Karnataka, India

Correspondence:

Dr. H. S. Drupad, No. 19, $2^{\text {nd }}$ Cross, $2^{\text {nd }}$ Main, $2^{\text {nd }}$ Block, Nandhini Layout, Bengaluru - 560 096, Karnataka, India.

E-mail: dhrupi@gmail.com for treating the emergency condition among health care professionals..$^{[6-8]}$

The aims and objectives of this study were to assess the knowledge of interns, medical students, and nursing students regarding anaphylaxis and to ascertain the knowledge regarding dose, route of administration, and concentration of the drug(s) used for its management.

\section{Materials and Methods}

This cross-sectional study was conducted in a tertiary

This is an open access article distributed under the terms of the Creative Commons Attribution-NonCommercial-ShareAlike 3.0 License, which allows others to remix, tweak, and build upon the work non-commercially, as long as the author is credited and the new creations are licensed under the identical terms.

For reprints contact: reprints@ @medknow.com

How to cite this article: Drupad HS, Nagabushan H. Level of knowledge about anaphylaxis and its management among health care providers. Indian J Crit Care Med 2015;19:412-5. 
care teaching hospital after obtaining permission from the Institutional Ethical Committee. Health care providers (interns, final year nursing students and MBBS Phase-II) were included in the study. A questionnaire was developed comprised of ten questions, regarding knowledge about anaphylaxis and the drugs used in its management (Appendix 1).

Knowledge regarding anaphylaxis was ascertained based on the number of questions each participant answered correctly. The response to the individual questions for the subjects in each group was analyzed separately. The data were presented both as numbers and percentages.

Descriptive statistics was analyzed using Epi-data analysis version V2.2.2.178 software (Epidata association from Denmark). The results were analyzed using the Chi-square test, and $P<0.05$ was considered as statistically significant.

\section{Results}

A total of 265 subjects participated in this study, of which 99 were $2^{\text {nd }}$ year medical students, 101 medical interns, and 65 were nursing students.

Of 265 subjects, 175 answered correctly the first question (\#1) regarding to which type of hypersensitivity reaction anaphylaxis belongs. One hundred and fifty-one (56.9\%) subjects answered correctly the second question (\#2), indicating that they would select adrenaline as the first line of drug for anaphylaxis. Among 151 subjects 40 (26.4\%) answered the correct dose of adrenaline of which $25(16.5 \%)$ of subjects selected that the preferred method of administration was intramuscular injection [Figure 1], 14 (9.2\%) selected subcutaneous injection, only eight (5.2\%) selected intravenous injection.

The response to the first two questions (\#1,2) was almost similar $(65 \%, 69 \%)$ among interns and MBBS-II

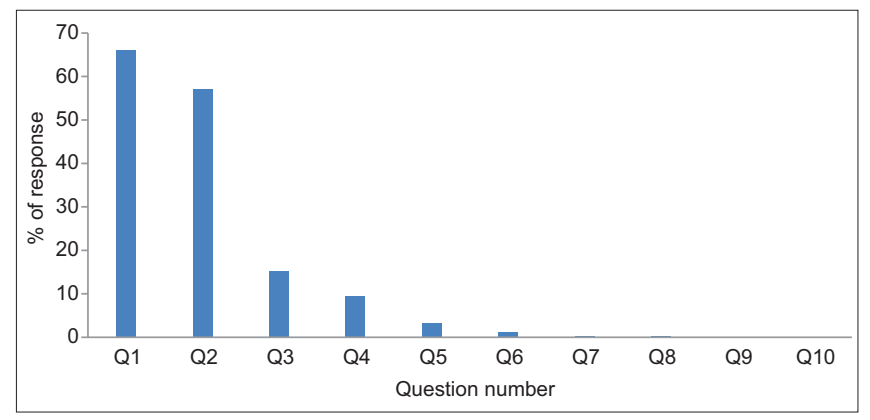

Figure I: Total percentage of correct response for each question students, respectively, when compared to the nursing students (37\%). For the next three questions (\#3, 4, 5) regarding the dose, route and site of administration, medical students had better knowledge $(27 \%, 47 \%$, and $40 \%)$ than interns $(16 \%, 19 \%$, and $17 \%)$ and nursing students $(11 \%, 18 \%$, and $6 \%)$ respectively. The responses to the questions $(\# 6,7,8)$ related to the concentration of adrenaline for the intravenous, intramuscular and subcutaneous route, were answered incorrectly by all three groups [Figure 2].

There was a statistical significant difference between medical students, interns and nursing students in response to questions $(\# 2,4,5)$ related to the first drug of choice, the route, and the site of administration of drug $(P<0.001)$ for the treatment of anaphylaxis, showing that medical students had more knowledge in these areas [Table 1].

\section{Discussion}

Anaphylaxis, an acute life-threatening emergency condition, requires immediate treatment in order to prevent further progression and to prevent complications.

The main purpose of this study was to assess the existing knowledge of interns, nursing students, and MBBS Phase II students regarding anaphylaxis and its medical management.

It was observed that none of the subjects answered all the questions correctly. When the response to the individual questions were analyzed, $65.6 \%$ of subjects answered correctly to the question related to anaphylaxis (i.e., question numbers 1 and 2) and the response rate was poor in areas related to the medical management of anaphylaxis.

Previous studies have shown that $90.1 \%$ of medical professionals prefer adrenaline as the first line drug, with $38.3 \%$ preferring intramuscular route and $51.7 \%$ preferring intravenous adrenaline. ${ }^{[9]}$ Our study has

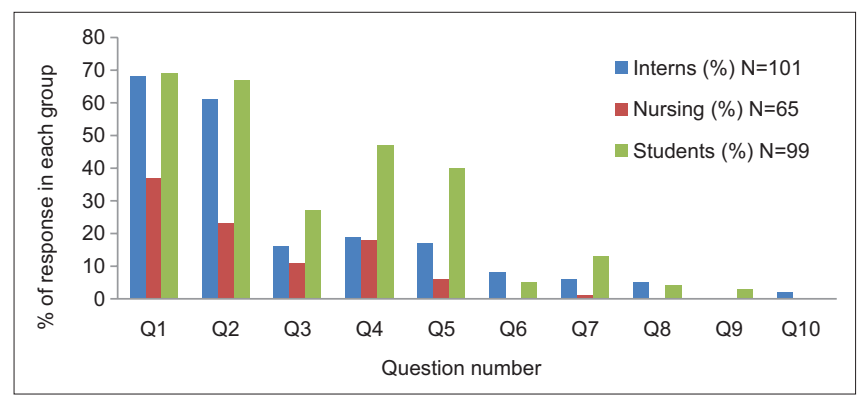

Figure 2: Percentage of correct response in each group 


\begin{tabular}{|c|c|c|c|c|c|}
\hline Questions & $\begin{array}{c}\text { Interns } \\
(\%) \\
(n=101)\end{array}$ & $\begin{array}{c}\text { Nursing } \\
(\%) \\
(n=65)\end{array}$ & $\begin{array}{c}\text { Students } \\
(\%) \\
(n=99)\end{array}$ & $\begin{array}{c}\text { Total } \\
(n=265)\end{array}$ & $\begin{array}{c}\text { Chi-square } \\
\text { (P) }\end{array}$ \\
\hline \multicolumn{6}{|l|}{$\overline{Q I}$} \\
\hline Correct & 68 & 37 & 69 & 174 & $3.04 I(0.219)$ \\
\hline Not correct & 33 & 28 & 30 & 91 & \\
\hline \multicolumn{6}{|l|}{ Q2 } \\
\hline Correct & 61 & 23 & 67 & $15 \mid$ & $17.468(<0.001)$ \\
\hline Not correct & 40 & 42 & 32 & 114 & \\
\hline \multicolumn{6}{|l|}{ Q3 } \\
\hline Correct & 16 & II & 27 & 54 & $4.660(0.097)$ \\
\hline Not correct & 85 & 54 & 72 & 211 & \\
\hline \multicolumn{6}{|l|}{ Q4 } \\
\hline Correct & 19 & 18 & 47 & 84 & $19.610(<0.001)$ \\
\hline Not correct & 82 & 47 & 52 & 181 & \\
\hline \multicolumn{6}{|l|}{ Q5 } \\
\hline Correct & 17 & 06 & 40 & 63 & $25.38 \mathrm{I}(<0.00 \mathrm{I})$ \\
\hline Not correct & 84 & 59 & 59 & 202 & \\
\hline \multicolumn{6}{|l|}{ Q6 } \\
\hline Correct & 08 & 0 & 05 & 13 & $5.326(0.070)$ \\
\hline Not correct & 93 & 65 & 94 & 252 & \\
\hline \multicolumn{6}{|l|}{ Q7 } \\
\hline Correct & 06 & 01 & 13 & 20 & 8.161 (0.017) \\
\hline Not correct & 95 & 64 & 86 & 245 & \\
\hline \multicolumn{6}{|l|}{ Q8 } \\
\hline Correct & 05 & 0 & 04 & 09 & $3.154(0.207)$ \\
\hline Not correct & 96 & 65 & 95 & 256 & \\
\hline \multicolumn{6}{|l|}{ Q9 } \\
\hline Correct & 0 & 0 & 3 & 3 & $5.088(0.079)$ \\
\hline Not correct & 101 & 65 & 96 & 262 & \\
\hline \multicolumn{6}{|l|}{ Q10 } \\
\hline Correct & 02 & 0 & 0 & 02 & $3.272(0.195)$ \\
\hline Not correct & 99 & 65 & 99 & 263 & \\
\hline
\end{tabular}

shown that the majority of subjects $(56.9 \%)$ preferred adrenaline as the first line drug for the treatment of anaphylaxis. Of 151 subjects, 16.5\% preferred intramuscular injection as the most appropriate route of administration. This shows that the level of knowledge in our study was lower when compared to previous study. ${ }^{[9]}$

Among the study subjects, medical students had better knowledge of anaphylaxis as regards the type of hypersensitivity reaction and as to which drug is used for first line treatment. Another study has shown that $80(73.3 \%)$ of participants correctly opted to use adrenaline as first-line treatment for anaphylaxis. ${ }^{[10]}$ In that study, $84.6 \%$ were $2^{\text {nd }}$ year students and $74.2 \%$ interns. In comparison, our study revealed that $67(67.6 \%)$ medical students, $61(60.3 \%)$ of interns and $23(35.3 \%)$ of nursing students chose adrenaline $(P<0.001)$.

In one prior study, the reason for not choosing adrenaline as first line drug by junior doctors was probably due to their concern with its potential adverse effect. ${ }^{[1]}$

Another study comparing two district hospitals has shown that there was a lack of knowledge in a significant number of senior and junior doctors regarding the dose, route, and concentration of adrenaline. ${ }^{[12]}$ Our study also showed similar results.

In our study, of the 151 subjects who had answered adrenaline as the first line drug, only 40 knew the correct dose of adrenaline, out of which 25 subjects selected intramuscular injection as the preferred route of administration.

The standard pediatric dose is $0.01 \mathrm{mg} / \mathrm{kg}$, but the majority of the participants were unable to answer the correct dose. There was a lack of knowledge about the pediatric dose, the route and the concentration of adrenaline.

The main limitation of our study was that it was a single-centered study with a small sample size and included only interns, medical, and nursing students.

There is a need for the development of interventional strategies to fill the knowledge gap for the ideal anaphylaxis management.

\section{Conclusion}

Knowledge regarding anaphylaxis and its management is a basic requirement that every health care providers must acquire for the appropriate treatment of all patients. In our study, there was a lack of knowledge regarding the medical management of anaphylaxis in interns, MBBS Phase II students, and nursing students. Proper initial training and periodic review and reinforcement of the steps in the treatment of anaphylaxis is necessary for all health care providers to achieve better patient care.

\section{Financial support and sponsorship}

Nil.

\section{Conflicts of interest}

There are no conflicts of interest.

\section{References}

1. Lieberman P, Nicklas RA, Oppenheimer J, Kemp SF, Lang DM, Bernstein DI, et al. The diagnosis and management of anaphylaxis practice parameter: 2010 update. J Allergy Clin Immunol 2010;126:477-80.e1

2. Frank AK. Allergies, anaphylaxis and systemic mastocytosis. In: Longo DL, editor. Harrison's Principles of Internal Medicine. $18^{\text {th }} \mathrm{ed}$., Vol. 2. USA:McGrew Hill; 2012. p. 2709-10.

3. Lieberman P, Camargo CA Jr, Bohlke K, Jick H, Miller RL, Sheikh A, et al. Epidemiology of anaphylaxis: Findings of the American College of Allergy, Asthma and Immunology Epidemiology of Anaphylaxis Working Group. Ann Allergy Asthma Immunol 2006;97:596-602.

4. Simons FE. Anaphylaxis: Recent advances in assessment and treatment. 
J Allergy Clin Immunol 2009;124:625-36.

5. Sheikh A, Shehata YA, Brown SG, Simons FE. Adrenaline (epinephrine) for the treatment of anaphylaxis with and without shock. Cochrane Database Syst Rev 2008;(4):CD006312.

6. Baccioglu A, Ucar EY. Level of knowledge about anaphylaxis among health care providers. Tuberk Toraks 2013;61:140-6.

7. Jose R, Clesham G.J. Survey of the use of epinephrine (adrenaline) for anaphylaxis by junior hospital doctors. Postgrad Med J 2007;83:610-1.

8. Droste J, Narayan N. Hospital doctors' knowledge of adrenaline (epinephrine) administration in anaphylaxis in adults is deficient. Resuscitation 2010;81:1057-8.

\section{Appendix 1}

\section{Anaphylaxis and its management}

\section{Questionnaire}

- What type of hypersensitivity reaction is Anaphylaxis?

- What is the first line of drug for anaphylaxis?

- What is the dose of the drug?

- What is the most preferred route used to administer the drug?

- What is the most common site?

- What is the concentration of drug for IV route?

- What is the concentration of drug for IM route?

- What is the concentration of drug for SC route?

- What is the paediatric dose of the drug?

- What is the concentration of the drug available in our hospital?
9. Prabhu SB, Yasmeen M. Treatment of anaphylaxis in adults: A questionnaire survey at S. Nijalingappa medical college hospital, Bagalkot, India. J Clin Diagn Res [Ser Online] 2010;4:3474-9.

10. Adiga S, Nayak V, Bairy KL. Treatment of anaphylaxis in adults: A questionnaire survey. Online J Health Allied Sci 2008;7:6.

11. Grabenhenrich L, Hompes S, Gough H, Ruëff F, Scherer K, Pföhler C, et al. Implementation of anaphylaxis management guidelines: A register-based study. PLoS One 2012;7:e35778.

12. Droste J, Narayan N. Anaphylaxis: Lack of hospital doctors' knowledge of adrenaline (epinephrine) administration in adults could endanger patients' safety. Eur Ann Allergy Clin Immunol 2012;44:122-7. 